\title{
Inhalational Steroids and Iatrogenic Cushing's Syndrome
}

\author{
A.V. Raveendran
}

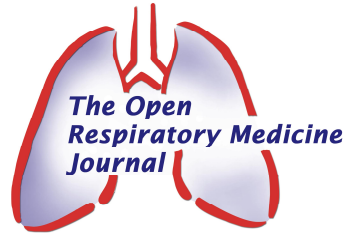

Department of Internal Medicine, Government Medical College \& Hospitals, Kottayam, Kerala-686008, India

\begin{abstract}
Bronchial asthma (BA) and Allergic rhinitis (AR) are common clinical problems encountered in day to day practice, where inhalational corticosteroids (ICS) or intranasal steroids (INS) are the mainstay of treatment. Iatrogenic Cushing syndrome (CS) is a well known complication of systemic steroid administration. ICS /INS were earlier thought to be safe, but now more and more number of case reports of Iatrogenic Cushing syndrome have been reported, especially in those who are taking cytochrome P450 (CYP 450) inhibitors. Comparing to the classical clinical features of spontaneous Cushing syndrome, iatrogenic Cushing syndrome is more commonly associated with osteoporosis, increase in intra-ocular pressure, benign intracranial hypertension, aseptic necrosis of femoral head and pancreatitis, where as hypertension, hirsuitisum and menstrual irregularities are less common. Endocrine work up shows low serum cortisol level with evidence of HPA (hypothalamo-pituitary-adrenal) axis suppression. In all patients with features of Cushing syndrome with evidence of adrenal suppression always suspect iatrogenic CS. Since concomitant administration of cytochrome P450 inhibitors in patients on ICS/INS can precipitate iatrogenic CS, avoidance of CYP450 inhibitors, its dose reduction or substitution of ICS are the available options. Along with those, measures to prevent the precipitation of adrenal crisis has to be taken. An update on ICS-/INS- associated iatrogenic CS and its management is presented here.
\end{abstract}

Keywords: Allergic rhinitis (AR), bronchial asthma (BA), chronic obstructive pulmonary disease (COPD), Cushing syndrome (CS), HPA (hypothalamo-pituitary-adrenal) axis, inhalational corticosteroids (ICS), intranasal steroids (INS).

\section{INTRODUCTION}

Bronchial asthma and allergic rhinitis are the common clinical problems seen in patients with naso-bronchial hyperresponsiveness. Inhaled corticosteroids (ICS) and intranasal corticosteroids (INC) are the commonly prescribed medications for these conditions. Role of ICS in the management of chronic obstructive pulmonary disease (COPD) is controversial, though they are commonly prescribed along with inhalational bronchodilators. Even though ICS and INS are considered to be safe, systemic side effects can occur, that includes iatrogenic Cushing syndrome. This side effect, although well known, still remains an under-recognized cause of Cushing syndrome. Cushingoid features with evidence of adrenal suppression almost always indicate iatrogenic Cushing syndrome due to exogenous steroid administration. This review highlights the pathogenic mechanisms, clinical features, diagnostic evaluation and management of iatrogenic Cushing syndrome secondary to use of ICS and INS.

\section{BRONCHIAL ASTHMA AND INHALATIONAL STEROIDS}

Bronchial asthma (BA) is characterized by airway edema, mucus hyper secretion, and cellular infiltration, along with bronchospasm [1]. This inflammatory reaction can lead to reversible airway obstruction in patients with BA, and

*Address correspondence to this author at the Department of Internal Medicine, Government Medical College \& Hospitals, Kottayam, Kerala686008, India; Tel: 919656429904; E-mail: raveendranav@yahoo.co.in
Corticosteroids, the powerful anti-inflammatory agents target this mechanism.

Systemic corticosteroids are used only for severe exacerbations and for chronic maintenance treatment of patients with severe BA, because of the higher incidence of side effects. The invention of inhalational corticosteroids in the 1970s and various convincing clinical trials during the late 1980 s demonstrated its superiority over other classes of drugs used in asthma treatment [2]. It showed a reduction in mortality and morbidity in patients with BA. The first Global Initiative for Asthma consensus in the early 1990's further emphasised the significance of ICS in the treatment of asthma [3].

The major advantage of delivery of steroids by inhalational route is the reduced incidence of systemic side effects and therefore, practically ICS have replaced systemic steroids in the treatment of BA, except during emergencies. The dose of inhaled steroid is much lower than the oral dose (ratio 1:20) required to achieve the same therapeutic effects [4].

Various clinical trials proved that ICS in Bronchial asthma significantly reduce the inflammation and hyperresponsiveness of airways, thereby improving lung function, decreasing the severity of symptoms and occurrence of acute exacerbation $[5,6]$.

\section{MECHANISM OF ACTION OF STEROIDS IN BA}

Corticosteroids interfere with the various pathways involved in the process of airway inflammation in BA, by binding to specific DNA sequences [7]. This binding leads to 
alteration in gene transcription and protein synthesis, resulting in reduction of airway inflammation, by reducing the production of various inflammatory mediators from cells like macrophages, eosinophils, lymphocytes, mast cells and dendritic cells $[8,9]$.

\section{ROLE OF ICS IN COPD}

Chronic obstructive pulmonary disease (COPD) is characterized by air flow limitation that is not fully reversible, in contrast to bronchial asthma, which is associated with reversible airway obstruction due to airway hyper-responsiveness and inflammation [10, 11]. In bronchial asthma ICS is the mainstay of treatment but in COPD, its role is still controversial [12].

Many patients with COPD share the features of airway hyper-responsiveness with $\mathrm{BA}$, leading to considerable overlap between these two, and this is the basis of Dutch hypothesis which states that COPD and bronchial asthma are part of the spectrum of the same basic disease. But the British hypothesis states that both are entirely different [13, 14].

Role of ICS is controversial in patients with COPD and there is no definite evidence to say that it may alter mortality. But some studies showed that it may delay the rate of decline of lung function and reduce the frequency of exacerbation [15].

ICS should be considered in COPD patients with severe disease, frequent exacerbations despite optimal therapy with bronchodilators and those having significant reversibility of airway obstruction with inhaled bronchodilators (i.e., mixed asthma and COPD group) [16].

Use of ICS are associated with increased risk of pneumonia, tuberculosis, easy bruising, osteoporosis, diabetes, oro-pharyngeal candidiasis, hoarseness of voice and even iatrogenic CS in patients with COPD, where the risk-benefit ratio has to be considered before starting steroids [17-24].

\section{FATE OF ICS IN THE BODY}

Use of various delivery systems for inhaled corticosteroids results in high amount of oro-pharyngeal deposition of the drug (up to $80 \%$ with pressurized metered-dose inhalers [MDI] and dry powder inhalers) that is subsequently swallowed, absorbed from GIT, undergo first-pass metabolism in the liver, and reaches the systemic circulation leading to systemic side effects [25]. Use of spacer device can reduce the amount swallowed to as little as $10 \%$. Rinsing the mouth after the use of ICS can also reduce the oropharyngeal deposition of the drug. The oral bioavailability of older ICS are high, as in beclomethasone, which is about $20 \%$, compared to newer drugs like, fluticasone where it is about $1 \%$, and mometasone where it is less than $1 \%$ [26]. Ciclesonide, a newer ICS which is a pro-drug, becomes activated only after getting deposited in the lung tissues. ICS are also directly absorbed from the lung after deposition in the respiratory tract following inhalation [27].

Alveolar deposition of ICS give rise to higher systemic exposure compared to the more proximal deposition in the airways. This is because the particles deposited in the ciliated airways are cleared by muco-ciliary clearance mechanism, and the barrier to diffusion in the ciliated airways may be less permeable that in the alveolar air spaces. Making average diameter of aerosol smaller reduces the amount of oro-pharyngeal deposition of the drug, and increases the alveolar deposition [28, 29]. The total amount of steroids that enters the systemic circulation, is the sum of the quantity that reaches the systemic circulation from the oropharayngal deposition of the ICS, after absorption in the GI tract and the first-pass metabolism in the liver (oral bioavailability), plus the quantity that is absorbed directly from the lungs (pulmonary bio-availability). The fate of ICS in the body is shown in the Fig. (1).

\section{PHARMACOLOGICAL PROPERTIES OF THE ICS}

The commonly available ICS are beclomethasone, budesonide, fluticasone, flunisolide, mometasone, triamcinolone, ciclesonide and budesonide [30]. The choice of ICS depends on a number of factors, including potency, systemic absorption, delivery system and the cost. Even though ICS are considered to be relatively safe, various local and systemic side effects are reported [31].

Lung deposition refers to the amount of inhaled drug that get deposited in the lung and act at the site of inflammation. So a high lung deposition of ICS is a desirable property, leading to high therapeutic efficacy. Various factors influence the pulmonary deposition of ICS [32]. They are (1) the physical properties of the ICS; (2) the drug delivery system; (3) particle size and (4) patient characteristics such as age, inhalational technique, and the severity of asthma. Ciclesonide and beclomethasone are having greatest lung deposition [33].

If the particle size of ICS is between 1-5 $\mu \mathrm{m}$, they are deposited in the bronchi and bronchioles more likely, where as particle size of $>5 \mu \mathrm{m}$ are more likely deposited in the oropharayngal cavity, and very small particles $(<1 \mu \mathrm{m})$ are either deposited in the upper airways or exhaled out [34]. So the particle size determine both therapeutic efficacy and safety profile of ICS. The smallest particle sizes is for Beclomethasone and ciclesonide delivered by MDI.

Ciclesonide and BDP are pro-drugs which are inactive when inhaled, and subsequently activated into desciclesonide and 17-BMP by esterase enzyme present in the lung epithelium. These pro-drugs are inactive till they are activated by esterase enzymes in the lung; and hence associated with lower incidence of side effects compared to other ICS administered in the active form (e.g., fluticasone and budesonide). Within the oro-pharynx the bio-activation of ciclesonide is very low, resulting in fewer incidence of systemic side effects compared to budesonide and fluticasone [35].

The degree of plasma protein binding of ICS reduces their potential for systemic side effects because, the pharmacological activity depends only on the amount of free drug. The protein binding is rapid and reversible, and is generally to albumin. Therefore, high degree of plasma protein binding reduces the systemic side effects. Since Ciclesonide and des-ciclesonide are highly protein-bound 


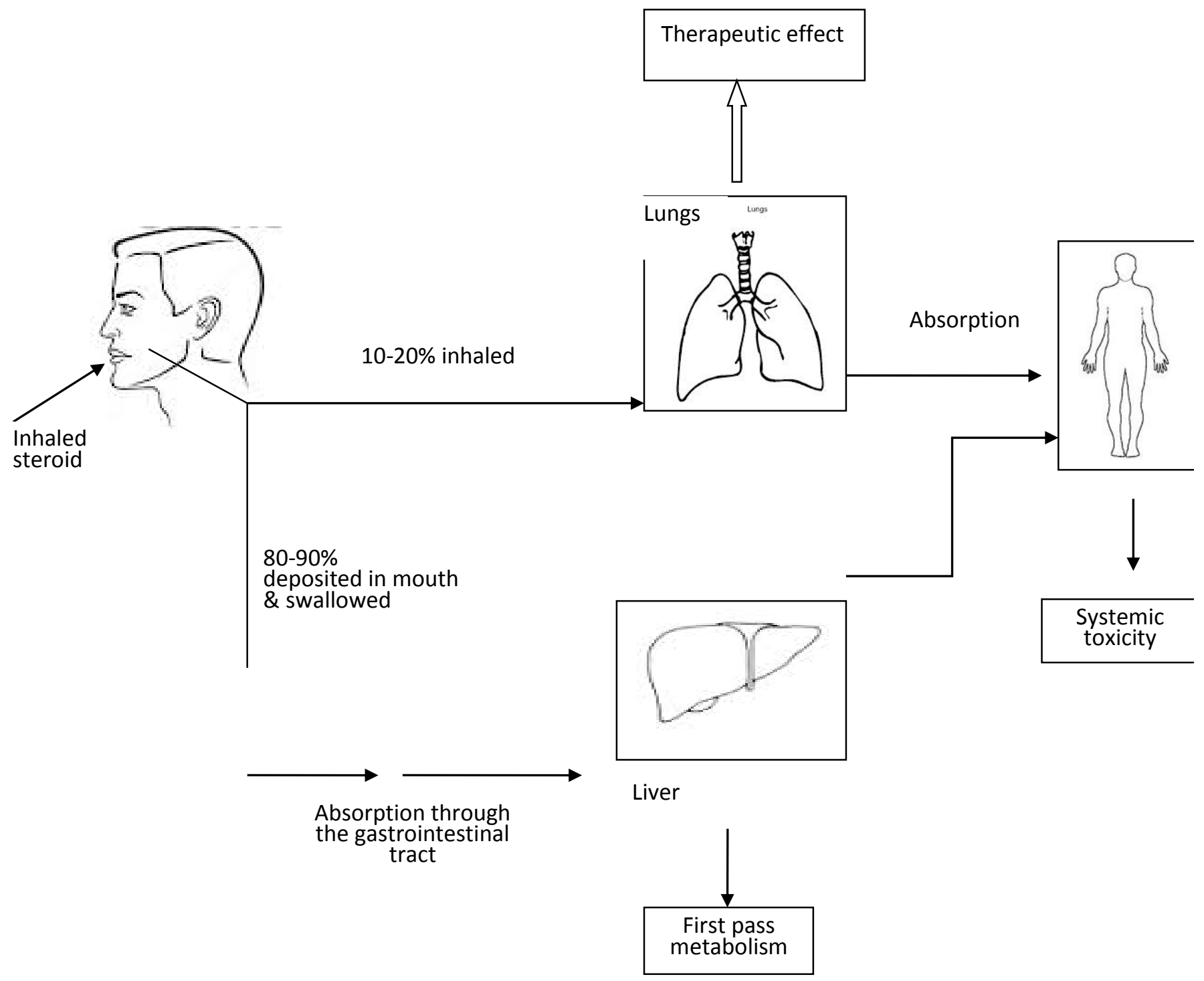

Fig. (1). The fate of Inhaled corticosteroids in the body.

$(99 \%)$ their systemic side-effects and adrenal suppression are minimal $[36,37]$.

After systemic absorption, ICS are rapidly metabolised by the liver. Maximum clearance rate by the liver of about $90 \mathrm{~L} / \mathrm{hr}$ is seen, which is equal to the hepatic blood flow. A short-half life and a high metabolic clearance rate reduce the systemic toxicity. The elimination half-lives of the ICS varies from 14.4 hours for fluticasone to as short as 0.5 hours for des-ciclesonide.

The pulmonary residence time (PRT) is the average time required for absorption of the molecules in to the systemic circulation after getting deposited in the lung [38]. PRT depends on lipophilicity and lipid conjugation of ICS. Lipophilicity helps ICS to pass through the cell membrane and, thereby increases the PRT and the volume of distribution of the drug [39]. Higher PRT increases the clinical efficacy of the ICS. However, increase in the volume of distribution after systemic absorption, leads to accumulation of the drug in various tissues causing increased risk for systemic toxic effects.
The lipid conjugation or fatty acid esterification is the process by which ICS form a reversible chemical bond with the fatty acid in the pulmonary tissue [40]. After lipid conjugation the drug-lipid complexes are retained there, making it available for binding to glucocorticoid receptors (GR) for longer duration (similar to a slow release preparation) prolonging the PRT of the ICS, making it convenient for single daily dosing [41]. Therefore, lipid conjugation of the ICS helps to improve the therapeutic efficacy, decreases the risk of development of systemic side effects and prolongs the duration of action.

\section{ALLERGIC RHINITIS AND INTRANASAL CORTICOSTEROIDS (INC)}

Intranasal corticosteroids (INC) are the main stay of treatment in patients with Allergic Rhinitis and Chronic Rhino Sinusitis [42, 43]. The INCs are available for treating allergic rhinitis since 1974 . The commonly used INC for the management of allergic rhinitis includes: beclomethasone dipropionate, budesonide, ciclesonide, flunisolide, fluticasone 
furoate, fluticasone propionate, mometasone furoate, and triamcinolone acetonide [44].

\section{MECHANISM OF ACTION OF INC}

The clinical efficacy of INC is because of its antiinflammatory effects [45]. Use of INC reduces the polyp size as well as the nasal symptoms, including nasal congestion, sneezing, rhinorrheoa, loss of smell, and postnasal drip in patients with chronic rhino-sinusitis with nasal polyps [46, 47].

\section{FATE OF INS IN THE BODY}

The fate of INC in the body is shown in the Fig. (2).

The systemic absorption rates are highest among the relatively older compounds like flunisolide, beclomethasone, and budesonide, where there is about $33 \%$ to $50 \%$ absorption of intra-nasally administered dose. The more lipophilic newer compounds like fluticasone propionate, and mometasone furoate, undergo rapid and extensive first-pass metabolism leading to negligible systemic absorption [48].

The order of lipid solubility for corticosteroids is as follows: mometasone furoate $>$ fluticasone propionate $>$ beclomethasone dipropionate $>$ budesonide $>$ triamcinolone acetonide $>$ flunisolide. Lipophilicity of Ciclesonide and desciclesonide are greater than fluticasone propionate.
Increased lipophilicity correlates with a greater deposition of the corticosteroid molecule in the nasal mucosa, greater binding affinity for and prolonged occupation of the GR, and, consequently, there is less unbound drug to interact with systemic GR, thereby potentially reducing the risk of systemic adverse effects. The intranasal lipid conjugation or fatty acid esterification increases the local residence time of the steroid molecules, and thereby allows once-daily dosing of many of the INC $[49,50]$.

\section{METABOLISM OF STEROIDS IN THE BODY AND DRUG INTERACTIONS}

The corticosteroids are metabolised in the liver with the help of cytochrome P450 enzyme system, mainly by the isoenzyme cytochrome P450 3A4 (CYP3A4) [51]. The drugs that inhibit this iso-enzyme increase the serum levels of corticosteroids, when co-administered. Similarly the inducers/stimulators of this iso-enzyme decrease the plasma steroid levels [52]. The drugs that inhibit CYP3A4 are shown in Table 1. The inhibitors of cytochrome P450, when co-administered, can increase the bio-availability of ICS/INS, leading to increased level of steroids in the systemic circulation, resulting in increased risk of systemic adverse effects. Among the inhaled CS, fluticasone and budesonide are mainly metabolized by CYP3A4. Beclomethasone is hydrolysed, and not metabolized by the

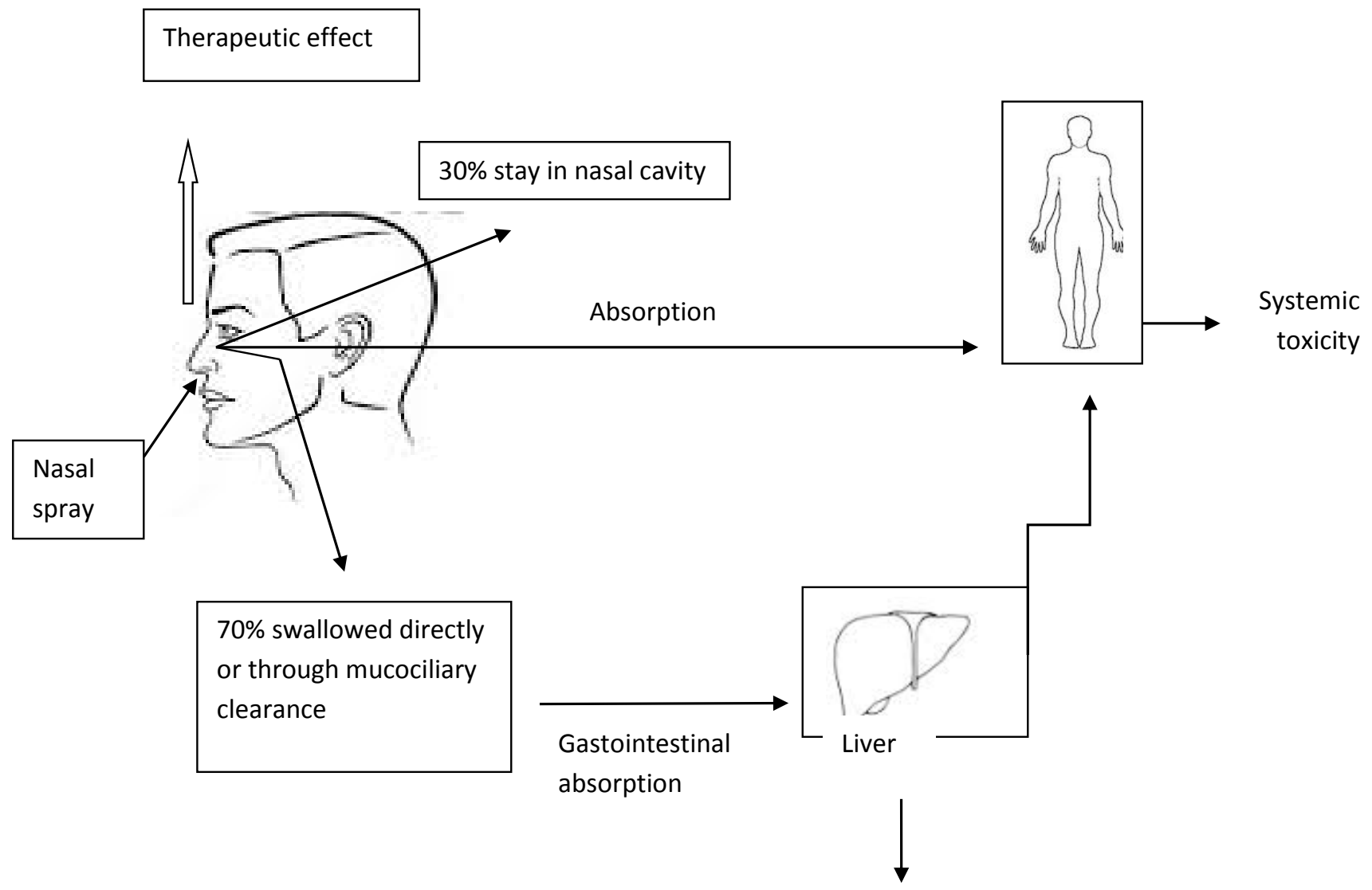

First pass metabolism

Fig. (2). Fate of Intranasal corticosteroids in the body. 
cytochrome P450, making this as a better choice in patients requiring inhaled therapy, while on a cytochrome P450 inhibitor [53, 54]. The lower risk of flunisolide for drug interaction is because of its weak CYP3A4 metabolism, low glucocorticoid receptor affinity, low lipophilicity and short elimination half-life.

Ritonavir, used for the treatment of HIV infection is a potent inhibitor of the hepatic CYP3A4 iso-enzyme. It is usually used at low doses to boost the levels of other protease inhibitors (PIs) in patients with HIV infection. Because of its potent hepatic CYP3A4 iso-enzyme inhibitory property, ritonavir and other PIs can result in various drugdrug interactions [55]. Since corticosteroids, such as ciclesonide, fluticasone, mometasone and triamcinolone, are mainly metabolised by hepatic CYP3A4, their metabolism will be inhibited when co-administered with ritonavir; leading to steroid accumulation, iatrogenic Cushing's syndrome (CS); and adrenal suppression. Co-administration of medications such as itraconazole, verapamil and diltiazem along with inhaled steroids can also result in iatrogenic CS.

The extent of steroid metabolism by the CYP3A4 isoenzyme is an important factor that determines the level of drug-drug interaction, when CYP3A4 inhibitors are coadministered. Other important properties that reduce the risk of drug-drug interaction include: 1) low systemic exposure because of the low glucocorticoid relative receptor binding affinity (RRA); 2) lower systemic oral bioavailability; 3) higher plasma protein binding; 4) shorter elimination halflife; 5) lower lipophilicity; 6) variation in CYP3A4 activity; 7) glucocorticoid receptor sensitivity; 8) glucocorticoid receptor polymorphism and 9) patients age.

Among the available ICS/INC, flunisolide and beclomethasone exhibit low RRA, short elimination half-life, low lipophilicity, and less dependence on CYP3A4 isozyme for its metabolism and fluticasone exhibits highest hypothalamic-pituitary-adrenal axis suppressive effect because of its pharmacokinetic properties, such as higher glucocorticoid RRA, higher lipophilicity, a longer elimination half-life and its high dependence for metabolism by CYP3A4.

\section{CUSHING SYNDROME}

Cushing syndrome (CS) is a group of clinical features caused by hypercortisolism [56]. CS takes its name from Harvey Cushing who, in 1912, first reported a patient with features of hypercorticolism [57]. CS can be due to endogenous causes such as pituitary tumour, ectopic ACTH production, adrenal tumour or exogenous causes like exogenous steroid administration. The term CS is used to describe the disease from all the causes, whereas Cushing's disease is reserved for cases of pituitary-dependent CS. Exogenous glucocorticoid administration is the most common cause of CS. Endogenous CS is less common [58].

Depending upon the level of plasma ACTH, the causes of Cushing syndrome can be broadly divided into two: 1) ACTH dependent CS and 2) ACTH-independent CS. Cushing's syndrome due to exogenous steroid administration is variably described as exogenous Cushing's, steroidinduced Cushing's or iatrogenic CS [59].

The pathophysiological mechanism varies depending upon the cause of CS [60]. In iatrogenic CS, the exogenous steroids suppress HPA axis resulting in decreased production of cortisol.

\section{CLINICAL FEATURES OF CUSHING'S SYNDROME}

Full blown CS is unmistakable clinically. But in mild and early cases, the clinical presentation is broad, and can be a diagnostic challenge. None of the clinical features of CS are pathognomonic, and many are nonspecific, adding to the diagnostic challenge.

The most common feature of Cushing's syndrome is progressive central (centripetal) obesity, which usually involves the face, neck, trunk, abdomen and, internally, spinal canal and mediastinum [61]. Fat accumulation, in the cheeks and in the temporal fossae results in "moon" face, in the back of neck results in "buffalo hump" or dorso-cervical fat pad and also enlarged fat pads fill the supra-clavicular fossae. But in pediatric cases, glucocorticoid excess may result in generalized obesity.

Table 1. Medications that alters the plasma glucocorticoid levels.

\begin{tabular}{|rl|}
\hline \multicolumn{2}{|c|}{ Medications that Alter the Plasma Glucocorticoid Levels } \\
\hline A. & Inducers of Cytochrome P450: Decreases GC Level \\
\hline 1. & Antiepileptics : Barbiturate, Carbamazepine, Phenytoin \\
2. & Bile acid sequestrants \\
3. & Antibiotics : Rifampicin \\
\hline B. $\quad$ Inhibitors of Cytochrome P450: Increases GC Level \\
\hline 1. Inhibitors of cytochrome P450 dependent CYP 3A4 inhibitors \\
\hline 1. & Antibiotics : Macrolide, Clarithromycin \\
2. & Anti fungal : Fluconazole, Itraconazole, Ketoconazole, Voriconazole \\
4. & Anti arrhythmic : Amiodarone, Lidocaine \\
5. & HIV drugs : Ritonavir, Indinavir \\
6. & HMG CoA reductase inhibitors: Atorvastatin \\
\hline 2. Inhibitors of cytochrome P450 dependent CYP 2D6 \\
\hline 1. & Antipsychotics/Antidepressents:Amitryptiline, Haloperidol, Resperidone, Clozapine, Fluoxetine. \\
\hline
\end{tabular}


The characteristic dermatologic changes of CS are usually not seen in other similar conditions such as pseudoCushing's [62]. Stretching of the fragile skin due to the enlarging trunk, breasts, and abdomen leads to development of broad, reddish-purple striae. The red-purple livid striae greater than $1 \mathrm{~cm}$ in width which is typical, and almost pathognomonic, are most commonly found over the abdomen, but are also present on the upper thighs, breasts, and arms.

Increased ACTH induces hyper-pigmentation, and it is not by excess cortisol. In humans ACTH is the principal hormone which induces pigmentation, and it acts via binding to melanocyte-stimulating hormone receptors [62]. Ectopic ACTH syndrome is most commonly associated hyperpigmentation, where as pituitary overproduction of ACTH is less commonly associated, and those with adrenal tumours or iatrogenic Cushing syndrome is usually not associated with hyper-pigmentation, because of suppressed ACTH secretion.

Menstrual abnormalities are also common in CS [63]. Signs of androgen excess like increased libido, hirsutism, virilization [including temporal balding, deepening of the voice, male body habitus, male escutcheon, and clitoral hypertrophy], are most common in women with adrenal carcinoma compared to other causes of Cushing's syndrome [64]. Adrenal glands are the major source of androgens in women. Signs of androgen excess are usually not seen in men with Cushing's syndrome. In comparison, signs of androgen excess are more common in women with adrenal carcinoma, less common in women with ACTH-dependent $\mathrm{CS}$, and not usually occur in women with adrenal adenomas.

Psychiatric abnormalities are seen in about 50\% of patients with CS.Common psychiatric abnormalities include agitated depression, lethargy, paranoia, overt psychosis, insomnia, emotional lability, irritability, anxiety and panic attacks [65].

Proximal muscle wasting and weakness are common in $\mathrm{CS}$, due to the catabolic effects of excess glucocorticoids on skeletal muscle, and are not seen in patients with pseudoCushing's syndrome [66]. The weakness in patients with CS is aggravated by associated hypokalemia which is due to increased mineralocorticoid activity.

Osteoporosis is common in patients with CS, which is caused by decreased absorption of calcium from the intestine, decreased bone formation, increased bone resorption, and decreased renal re-absorption of calcium [67]. Avascular necrosis of the femoral head occurs more commonly in patients with exogenous CS [68]. Low back pain is also very common. Glucose intolerance is common and frank diabetes can be seen in some cases, especially in patients with a family history of type 2 diabetes mellitus [69].

Hypertension is seen in up to $75 \%$ of cases. The mechanisms include mineralocorticoid effects of cortisol, the action of cortisol on peripheral and systemic vasculature, and activation of the renin-angiotensin system [70, 71]. Severe hypertension and hypokalemia are more prevalent in patients with CS secondary to ectopic ACTH [72]. Cardiovascular events are also more common in patients with CS, there by increasing the morbidity and mortality [73]. Patients with CS are more prone for infections, due to the inhibitory effects of glucocorticoids on the immune function. Increase in intraocular pressure, posterior sub-capsular cataract and retinal detachment are the ophthalmologic problems in CS [74].

The common clinical clues to differentiate ectopic ACTH secretion from the Cushing's disease are male sex, atypical presentation, fast progression, severe myopathy, very high cortisol/ACTH values and severe hypokalemia. Few features of Cushing's syndrome have more discriminatory value than others, which includes reddish purple striae, proximal muscle, weakness, plethora, bruising with no obvious trauma, and unexplained osteoporosis [75].

\section{CLINICAL PRESENTATION OF CS IN PAEDIATRIC PATIENTS}

Growth failure with associated gain in weight is one of the most important clinical features presents in paediatric CS [76]. Sleep disruption, muscular weakness, and problems with memory are less commonly seen in children's with CS, compared to adults. In paediatric CS generalized obesity is seen, in contrast to adult CS which is associated with central obesity [77].

\section{IATROGENIC CS}

Iatrogenic CS is the most common cause of CS [78]. The development of CS depends on the dose, duration, and potency of the corticosteroids used in clinical practice. Exogenous CS presents with the same signs and symptoms as spontaneous CS. But some features, such as an increase in intraocular pressure, benign intracranial hypertension, cataracts, osteoporosis, aseptic necrosis of the femoral head, and pancreatitis, are more common in iatrogenic than endogenous CS, whereas features like hypertension, hirsutism, and oligomenorrhea/amenorrhea are less prevalent (Table 2) [79-86]. The clinical manifestations of iatrogenic CS are more striking than that of spontaneous Cushing's, which occurs gradually. Generally, a Cushingoid appearance takes weeks or even months to develop depending upon the type and dose of the steroid used. However, it is difficult to predict doses and time courses at which CS will develop, because various factors like different potencies, different formulations, different modes of delivery of various glucocorticoids and varying levels of sensitivity of the individual patients to glucocorticoids, will complicate the issue.

Drug interaction is an important precipitating factor for iatrogenic CS, especially with co-administration of CYP450 inhibitors. Most of the case reports in patients using ICS are related to interaction with ritonavir, itraconazole, verapamil and diltiazem. Various case reports shows that in patients on ICS and PI, the duration of co-administration of corticosteroid with PI before the onset of symptoms ranges from 10 days to 5 years with a mean of 7.1 months $[87,88]$. Clinical features reported includes 'Cushingoid facies' or 'moon face', dorso-cervical fat pad (also known as 'buffalo hump'), central obesity and weight gain, facial hirsutism, striae and easy bruising, most of them were common symptoms associated with Cushing's syndrome. A comparison of iatrogenic and spontaneous CS is given in the Table 2. 
Table 2. A Comparison of Spontaneous Cushing Syndrome and Iatrogenic Cushings syndrome.

\begin{tabular}{|c|c|c|}
\hline H/o exogenous steroid intake & Absent & Present \\
\hline Psychological features & Less severe & More severe \\
\hline Hypertension & More common & Less common \\
\hline Menstrural irregularities & More common & Less common \\
\hline Glucoma, ocular features & Less common & More common \\
\hline Avascular necrosis & Less common & More common \\
\hline Benign intracranial hypertension & Less common & More common \\
\hline Serum cortisol & Increased & Suppressed \\
\hline ACTH & Increased / decreased & Suppressed \\
\hline Adrenal suppression & Absent & Present \\
\hline
\end{tabular}

Co-administration of ICS and PI in HIV positive patients can be problematic because of the diagnostic confusion between iatrogenic $\mathrm{CS}$ and the antiretroviral-associated lipodystrophy, since their overlapping clinical features can lead to delayed diagnosis of iatrogenic CS [89]. However, rapid weight gain, increased appetite, abdominal striae, easy bruising, facial hirsutism, facial plethora, and neuropsychological manifestations are commonly associated with CS where as peripheral atrophy is more commonly associated with lipodystrophy. The distinguishing feature of HIV-associated lipodystrophy is that visceral fat deposition is accompanied by normal or decreased (but not increased) amounts of subcutaneous fat. Lipodystrophy is a slow, chronic change of fat distribution, usually evolving over many years, compared to rapid evolution in iatrogenic CS [90].

\section{PSEUDO-CUSHING'S SYNDROME}

Some patients will have mild to moderate hypercortisolism due to chronic over-activity of the HPA axis without true CS. So there may be hypercortisolism, abnormal dexamethasone suppressibility and mild elevation of urinary free cortisol (UFC), causing diagnostic confusion with true CS, and is called Pseudo-Cushing's syndrome [91].

The test that helps to differentiate true from pseudoCushing's syndrome is dexamethasone suppression test followed by a CRH stimulation test. Patients with pseudoCushing's syndrome do not respond to CRH stimulation, while patients with true CS respond with a stimulated cortisol value of more than $1.4 \mu \mathrm{g} / \mathrm{dL}$.

\section{INVESTIGATIONS}

In a case of suspected CS, the laboratory evaluation starts with the demonstration of hyper-cortisolism by showing increased and basal serum cortisol, 24 hours urinary free cortisol excretion, mid night salivary or serum cortisol and non-supressibility after an overnight dexamethosone suppression test. Once the hyper-cortisolism is confirmed, the next step is to measure plasma ACTH level to see whether the condition is ACTH-dependent CS, due to either pituitary tumours or ectopic ACTH secretion; or ACTH independent CS, due to basic adrenal pathology [92].

However, the diagnostic evaluation in patients with Iatrogenic CS shows entirely different results. The endocrine workup in iatrogenic CS shows a low 24-hour urine cortisol, a very low serum cortisol level and a suppressed plasma ACTH level. The most valuable laboratory test is the detection of synthetic glucocorticoids in the urine by highpressure liquid chromatography $[93,94]$. Reduction in the level of DHEAS after starting ICS/INS is found to be an early marker of adrenal suppression [95]. A diagnostic algorithm of CS is shown in Fig. (3).

\section{TREATMENT}

In Iatrogenic CS due to ICS/INS, the possible treatment options include: (1) use of an alternative medication instead of steroids, such as an anti-cholinergic agent (e.g. ipratropium), a mast cell stabilizer (e.g. cromolyn), a leukotriene receptor antagonist (e.g. montelukast), or an antihistamine (2) if drug interaction is suspected, substituting the inhaled/intranasal corticosteroid with corticosteroid of less potential for drug interactions (3) if drug interaction is suspected in HIV positive individuals on PI, based on the drug resistance and treatment history, change the PI to another antiretroviral agent without CYP3A4 isozyme inhibitory activity (such as nonnucleoside reverse transcriptase inhibitor, chemokinereceptor 5 (CCR5 receptor) antagonist or integrase inhibitors (specifically raltegravir or dolutegravir), if this is allowable or 


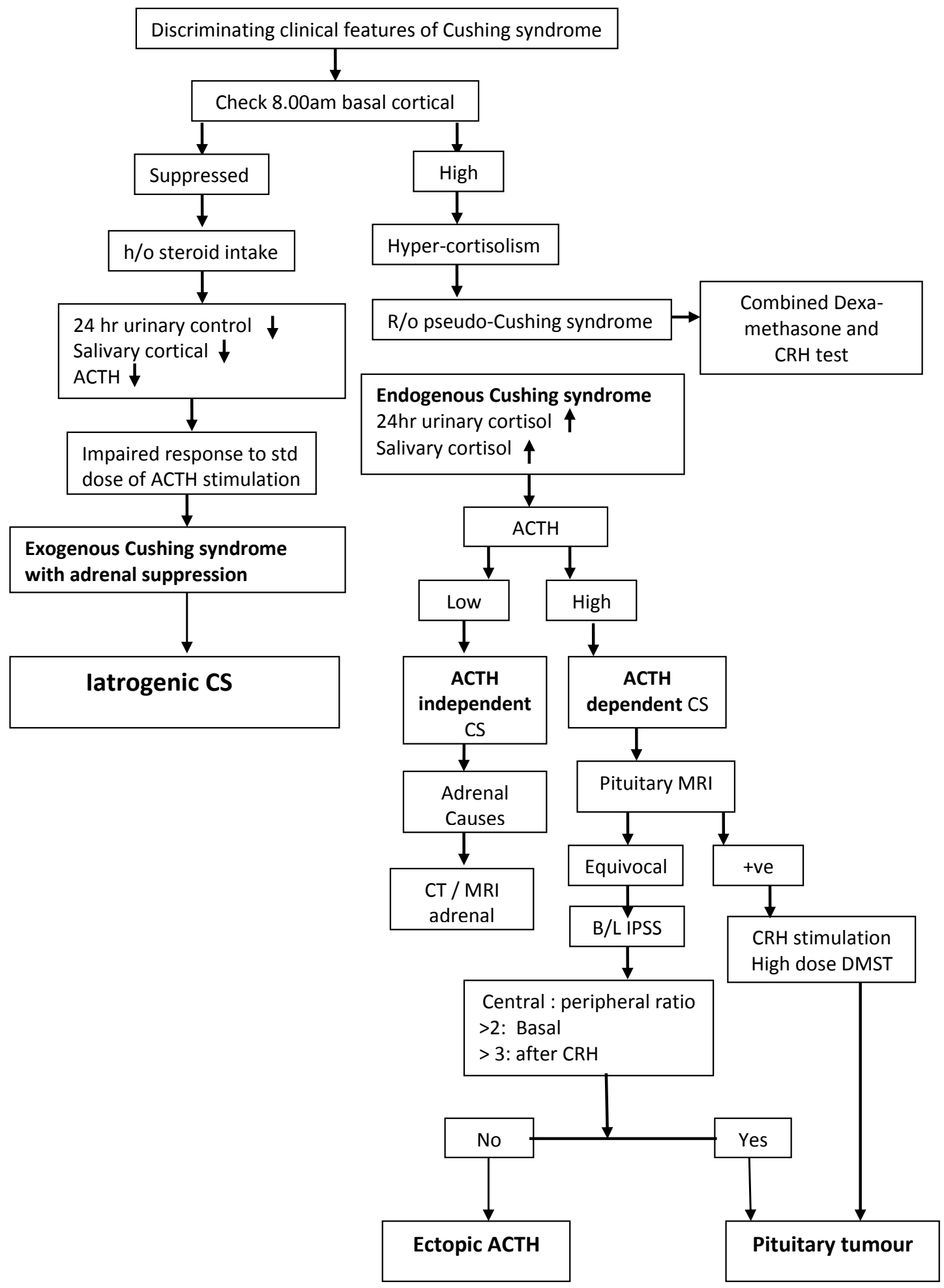

Fig. (3). The diagnostic evaluation of CS.

substituting the inhaled/intranasal corticosteroid with another corticosteroid with less potential for drug interactions and (4) use the lowest possible dose of ICS/INC along with CYP3A4 isozyme inhibitors, if both has to be continued depending upon the clinical condition [96].

In patients with iatrogenic $\mathrm{CS}$, adrenal suppression is common and should be evaluated for the potential need to initiate oral steroid replacement and its gradual tapering [97].
Iatrogenic CS is usually associated with evidence of Adrenal insufficiency $[98,99]$.

\section{PREVENTION OF IATROGENIC CS}

The goal for using all inhaled and intranasal corticosteroids are to (1) produce long-lasting and potent therapeutic effects at the site of action, (2) lower systemic 
bio-availability, and (3) minimize systemic adverse effects by rapid elimination of the absorbed drug. The ideal inhalational should have the properties shown in the Table 3.

Table 3. Properties of an ideal inhalational standard.

$\begin{array}{ll}\text { 1. } & \text { Particle size }<5 \mu \mathrm{m} \\ \text { 2. } & \text { Low systemic availability } \\ \text { 3. } & \text { Low Receptor binding affinity } \\ \text { 4. } & \text { On site activation/ Pro-drug } \\ \text { 5. } & \text { High lipid conjugation } \\ \text { 6. } & \text { High Protein Binding } \\ \text { 7. } & \text { Rapid clearance of systemically absorbed drug }\end{array}$

Inhaled or intranasal beclomethasone, budesonide and flunisolide are relatively safe and can be used in patients on CYP3A4 inhibitors. Based on the pharmacokinetic properties beclomethasone and budesonide, appear to be safer because of their lower binding affinity for glucocorticoid receptors and shorter elimination half-life, and flunisolide have a low risk of drug-drug interactions because of its low glucocorticoid RRA, low lipophilicity, weak CYP3A4 metabolism and short elimination half-life.

\section{CONCLUSION}

Uses of ICS/INS are associated with potential risk of development of Iatrogenic CS, especially with coadministration of CYP3A4 inhibitors. Clinical features of iatrogenic CS resemble that of spontaneous CS. In HIV infected patients on ICS/INS and PI, development of iatrogenic CS can be confused with anti-retroviral associated lipodystrophy, leading to delay in diagnosis. Cushingoid features with adrenal suppression and low serum cortisol are the features of iatrogenic CS. Reducing the dose of the steroids to minimum, substituting steroids with less potent steroids or with other alternative drugs and avoiding drug interactions are the various options for the prevention/ treatment of Iatrogenic CS, along with steroid supplementation and gradual tapering in case of associated adrenal insufficiency.

\section{CONFLICT OF INTEREST}

The author confirms that this article content has no conflict of interest.

\section{ACKNOWLEDGEMENTS}

Declared none.

\section{REFERENCES}

[1] Hargreave FE, Nair P. The definition and diagnosis of asthma. Clin Exp Allergy 2009; 39: 1652-8.

[2] Barnes PJ. Will it be steroids forever? Clin Exp Allergy 2005; 35 : 843-5.

[3] Global strategy for asthma management and prevention: NHLBI/WHO workshop report March 1993. National Institutes of Health; 2002. Publication number 95-36-59 issued January 1995.

[4] Kelly HW. Comparison of inhaled corticosteroids: An update. Ann Pharmacother 2009; 43: 519-27.
[5] Blais L, Ernst P, Boivin JF, et al. Inhaled corticosteroids and the prevention of readmission to hospital for asthma. Am J Respir Crit Care Med1998; 158: 126-32.

[6] Suissa S, Ernst P, Benayoun S, et al. Low-dose inhaled corticosteroids and the prevention of death from asthma. N Engl J Med 2000; 343: 332-6.

[7] Barnes PJ, Adcock IM. How do corticosteroids work in asthma? Ann Intern Med 2003; 139: 359-70.

[8] Umland SP, Schleimer RP, Johnston SL. Review of the molecular and cellular mechanisms of action of glucocorticoids for use in asthma. Pulm Pharmacol Ther 2002; 15: 35-50.

[9] Yudt MR, Cidlowski JA. The glucocorticoid receptor: Coding a diversity of proteins and responses through a single gene. Mol Endocrinol 2002; 16: 1719-26.

[10] Global initiative for chronic obstructive lung disease (GOLD). Global Strategy for the Diagnosis, Management, and Prevention of Chronic Obstructive Pulmonary Disease. Updated 2011. www.goldcopd.com [Accessed 1 September 2014].

[11] Qaseem A, Wilt TJ, Weinberger SE, et al. Diagnosis and management of stable chronic obstructive pulmonary disease: A clinical practice guideline update from the American College of Physicians, American College of Chest Physicians, American Thoracic Society, and European Respiratory Society. Ann Intern Med 2011; 155:179-91.

[12] Suissa S, Barnes PJ. Inhaled corticosteroids in COPD: The case against. Eur Respir J 2009; 34: 13-6.

[13] Bafadhel M, McKenna S, Terry S, et al. Acute exacerbations of COPD: Identification of biological clusters and their biomarkers. Am J Respir Crit Care Med 2011; 184: 662-71.

[14] Boezen HM, Schouten JP, Weiss ST. The Dutch hypothesis on chronic nonspecific lung disease. Eur Respir Mon 2000; 15: 37-47.

[15] Suissa S, McGhan R, Niewoehner D, Make B. Inhaled corticosteroids in chronic obstructive pulmonary disease. Proc Am Thorac Soc 2007; 4: 535-42.

[16] Price D, Yawn B, Brusselle G, Rossi A. Risk-to-benefit ratio of inhaled corticosteroids in patients with COPD. Prim Care Respir J 2013; 22: 92-100.

[17] Lipworth BJ. Systemic adverse effects of inhaled corticosteroid therapy: A systematic review and meta-analysis. Arch Intern Med 1999; 159: 941-55.

[18] Ernst P, Gonzalez AV, Brassard P, Suissa S. Inhaled corticosteroid use in chronic obstructive pulmonary disease and the risk of hospitalization for pneumonia. Am J Respir Crit Care Med 2007; 176: $162-6$

[19] Sobieraj DM, White CM, Coleman CI. Benefits and risks of adjunctive inhaled corticosteroids in chronic obstructive pulmonary disease: A meta-analysis. Clin Ther 2008; 30: 1416-25.

[20] Brassard P, Suissa S, Kezouh A, Ernst P. Inhaled corticosteroids and risk of tuberculosis in patients with respiratory diseases. Am J Respir Crit Care Med 2011; 183: 675-8.

[21] Loke YK, Cavallazzi R, Singh S. Risk of fractures with inhaled corticosteroids in COPD: Systematic review and meta-analysis of randomised controlled trials and observational studies. Thorax 2011; 66: 699-708.

[22] Tashkin DP, Murray HE, Skeans M, Murray RP. Skin manifestations of inhaled corticosteroids in COPD patients: Results from Lung Health Study II. Chest 2004; 126: 1123-33.

[23] Garbe E, Suissa S, LeLorier J. Association of inhaled corticosteroid use with cataract extraction in elderly patients. JAMA $1998 ; 280$ : 539-43. [Erratum in: JAMA 1998; 280: 1830].

[24] Suissa S, Kezouh A, Ernst P. Inhaled corticosteroids and the risks of diabetes onset and progression. Am J Med 2010; 123: 1001-6.

[25] Derendorf H, Hochhaus G, Meibohm B, Mollmann H, Barth J. Pharmacokinetics and pharmacodynamics of inhaled corticosteroids. J Allergy Clin Immunol 1998; 101 (4 Pt 2): S440-6. Rohatagi S, Derandorf $\mathrm{H}$, Zech $\mathrm{K}$, et al. PK/PD of inhaled corticosteroids: The risk/benefit of inhaled ciclesonide [abstract]. J Allergy Clin Immunol 2003; 111(2 Suppl) (S218): 598.

[27] Dietzel K, Engelstätter R, Keller A. Ciclesonide: An on-site activated steroid. In: Hansel TT, Barnes PJ, Eds. New Drugs for asthma, allergy and COPD. Basle: Karger 2001; pp. 91-3.

[28] Sturton G, Persson C, Barnes PJ. Small airways: An important but neglected target in the treatment of obstructive airway diseases. Trends Phamacol Sci 2008; 29: 340-5. 
[29] Usmani OS, Biddiscombe MF, Barnes PJ. Regional lung deposition and bronchodilator response as a function of $\beta 2$-agonist particle size. Am J Respir Crit Care Med 2005; 172: 1497-504.

[30] Adamsa NP, Jonesb PW. The dose-response characteristics of inhaled corticosteroids when used to treat asthma: An overview of Cochrane systematic reviews. Respir Med 2006; 100: 1297-306.

[31] Kelly HW, Nelson HS. Potential adverse effects of the inhaled corticosteroids. J Allergy Clin Immunol 2003; 112: 469-78.

[32] Pritchard JN. The influence of lung deposition on clinical response. J Aerosol Med 2001; 14(Suppl 1): S19-26.

[33] Derendorf H, Nave R, Drollmann A, Cerasoli F, Wurst W. Relevance of pharmacokinetics and pharmacodynamics of inhaled corticosteroids to asthma. Eur Respir J 2006; 28: 1042-50.

[34] Howarth PH. Why particle size should affect clinical response to inhaled therapy. J Aerosol Med 2001; 14(Suppl 1): S27-34

[35] Mutch E, Nave R, Zech K, Williams FM. Esterases involved in the hydrolysis of ciclesonide in human tissues. Eur Respir J 2003; 22(Suppl 45): S267-8.

[36] Rohatagi S, Luo Y, Shen L, et al. Protein binding and its potential for eliciting minimal systemic side effects with a novel inhaled corticosteroid, ciclesonide. Am J Ther 2005; 12: 201-9.

[37] Rohatagi S, Arya V, Zech K, et al. Population pharmacokinetics and pharmacodynamics of ciclesonide. J Clin Pharmacol 2003; 43 : 365-78.

[38] Derendorf H, Hochhaus G, Mollmann H. Systemic disposition and effects of inhaled corticosteroids. In: Schleimer RP, O’Bryne PM, Szefler SJ, Brattsand R, Eds. Inhaled Steroids in Asthma. Optimizing effects in the airways. New York: Marcel Decker, Inc., 2002; pp. 3-33.

[39] Miller-Larsson A, Axelsson B-O, Brattsand R, Edsbacker S, Ingelf J. Relative lipophilicity of budesonide, fluticasone propionate, mometasone furoate, and ciclesonide. Preference of variable lipophilicity in airways versus systemic compartment [Abstract]. Am J Respir Crit Care Med 2003; 167: A773.

[40] Miller-Larsson A, Jansson P, Runstrom A, Brattsand R. Prolonged airway activity and improved selectivity of budesonide possibly due to esterification. Am J Respir Crit Care Med 2000; 162: 145561 .

[41] Miller-Larsson A, Mattsson H, Hjertberg E, Dahlba“ck M, Tunek A, Brattsand R. Reversible fatty acid conjugation of budesonide. Novel mechanism for prolonged retention of topically applied steroid in airway tissue. Drug Metab Dispos 1998; 26: 623-30.

[42] Bousquet J, Khaltaev N, Cruz AA, et al. Allergic rhinitis and its impact on asthma (ARIA) 2008 update (in collaboration with the World Health Organization, GA2- LEN and AllerGen). Allergy 2008; 63: 8-160.

[43] Meltzer EO. The Role of Nasal Corticosteroids in the treatment of rhinitis. Immunol Allergy Clin N Am 2011; 31: 545-60.

[44] Derendorf H, Meltzer EO. Molecular and clinical pharmacology of intranasal corticosteroids: Clinical and therapeutic implications. Allergy 2008; 63: 1292-300.

[45] Rhen T, Cidlowski JA. Antiinflammatory action of glucocorticoids-new mechanisms for old drugs. N Engl J Med 2005; 353: 1711-23.

[46] Lund VJ, Flood J, Sykes AP, et al. Effect of fluticasonein severe polyposis. Arch Otolaryngol Head Neck Surg 1998; 124: 513-8.

[47] Small CB, Hernandez J, Reyes A, et al. Efficacy and safety of mometasone furoate nasal spray in nasal polyposis. J Allergy Clin Immunol 2005; 116: 1275-81.

[48] Szefler SJ. Pharmacokinetics of intranasal corticosteroids. J Allergy Clin Immunol 2001;108(Suppl 1): S26-31.

[49] Waddell AN, Patel SK, Toma AG, et al. Intranasal steroid sprays in the treatment of rhinitis: Is one better than another? J Laryngol Otol 2003; 117: 843-5

[50] Joe S, Thambi R, Huang J. A systematic review of the use of intranasal steroids in the treatment of chronic rhinosinusitis. Otolaryngol Head Neck Surg 2008; 139: 340-7.

[51] Danielson PB. The cytochrome P450 superfamily: Biochemistry, evolution and drug metabolism in humans. Curr Drug Metab 2002; 3: 561-97.

[52] Daveluy A, Raignoux C, Miremont-Salamé G. Drug interactions between inhaled corticosteroids and enzymatic inhibitors. Eur J Clin Pharmacol 2009; 65: 743-5.

[53] De Wachter E, Malfroot A, De Schutter I, Vanbesien J, De Schepper J. Inhaled budesonide induced Cushing's syndrome in cystic fibrosis patients, due to drug inhibition of cytochrome P450. J Cyst Fibros 2003; 2: 72-5.

[54] Kedem E, Shahar E, Hassoun G, Pollack S. Iatrogenic Cushing's syndrome due to coadministration of ritonavir and inhaled budesonide in an asthmatic human immunodeficiency virus infected patient. J Asthma 2010, 47: 830-1.

[55] Samaras K, Pett S, Gowers A, McMurchie M, Cooper DA. Iatrogenic Cushing's syndrome with osteoporosis and secondary adrenal failure in human immunodeficiency virus-infected patients receiving inhaled corticosteroids and ritonavir-boosted protease inhibitors: Six cases. J Clin Endocrinol Metab 2005, 90: 4394-8.

[56] Newell-Price J, Bertagna X, Grossman AB, et al. Cushing's syndrome. Lancet 2006; 367(9522): 1605-17.

[57] Cushing $\mathrm{H}$. The basophil adenomas of the pituitary body and their clinical manifestations (pituitary basophilism). Bull Johns Hopkins Hosp 1932; 50: 137-95.

[58] Steffensen C, Bak AM, Rubeck KZ, Jorgensen JO. Epidemiology of Cushing's syndrome. Neuroendocrinology 2010; 92(Suppl 1): 15.

[59] Hopkins RL, Leinung MC. Exogenous Cushing's syndrome and glucocorticoid withdrawal. Endocrinol Metab Clin North Am 2005; 34: 371-84, ix.

[60] Soffer LJ, Iannaccone A, Gabrilove JL. Cushing's syndrome: A study of fifty patients. Am J Med 1961; 30:129.

[61] Wajchenberg BL, Bosco A, Marone MM, et al. Estimation of body fat and lean tissue distribution by dual energy X-ray absorptiometry and abdominal body fat evaluation by computed tomography in Cushing's disease. J Clin Endocrinol Metab 1995; 80: 2791-4.

[62] Mountjoy KG. The human melanocyte stimulating hormone receptor has evolved to become super-sensitive to melanocortin peptides. Mol Cell Endocrinol 1994; 102: R7-11.

[63] Lado-Abeal J, Rodriguez-Arnao J, Newell-Price JD, et al. Menstrual abnormalities in women with Cushing's disease are correlated with hypercortisolemia rather than raised circulating androgen levels. J Clin Endocrinol Metab 1998; 83: 3083-8.

[64] Hutter AM Jr, Kayhoe DE. Adrenal cortical carcinoma: Clinical features of 138 patients. Am J Med 1966; 41: 572-80.

[65] Kelly WF. Psychiatric aspects of Cushing's syndrome. QJM 1996; 89: 543-51.

[66] Ferrando AA, Stuart CA, Sheffield-Moore M, Wolfe RR. Inactivity amplifies the catabolic response of skeletal muscle to cortisol. Clin Endocrinol Metab 1999; 84: 3515-21.

[67] Adler RA, Rosen CJ. Glucocorticoids and osteoporosis. Endocrinol Metab Clin North Am 1994; 23: 641-54

[68] Felson DT, Anderson JJ. Across-study evaluation of association between steroid dose and bolus steroids and avascular necrosis of bone. Lancet 1987; 1(8538): 902-6.

[69] Catargi B, Rigalleau V, Poussin A, et al. Occult Cushing's syndrome in type-2 diabetes. J Clin Endocrinol Metab 2003; 88: 5808-13.

[70] Saruta T, Suzuki H, Handa M, et al. Multiple factors contribute to the pathogenesis of hypertension in Cushing's syndrome. J Clin Endocrinol Metab 1986; 62: 275-9.

[71] Sharma ST, Nieman LK, Cushing's syndrome: All variants, detection, and treatment. Endocrinol Metab Clin N Am 2011; 40: 379-91.

[72] Torpy DJ, Mullen N, Ilias I, Nieman LK. Association of hypertension and hypokalemia with Cushing's syndrome caused by ectopic ACTH secretion: A series of 58 cases. Ann N Y Acad Sci 2002; 970:134-44

[73] Mancini T, Kola B, Mantero F, et al. High cardiovascular risk in patients with Cushing's syndrome according to $1999 \mathrm{WHO} / \mathrm{ISH}$ guidelines. Clin Endocrinol (Oxf) 2004; 61: 768-77.

[74] Sayegh F, Weigelin E. Intraocular pressure in Cushing's syndrome. Ophthalmic Res 1975; 7: 390-4

[75] Ross EJ, Linch DC. Cushing's syndrome-killing disease: Discriminatory value of signs and symptoms aiding early diagnosis. Lancet 1982; 2(8299): 646-9.

[76] Greening JE, Storr HL, McKenzie SA, et al. Linear growth and body mass index in pediatric patients with Cushing's disease or simple obesity. J Endocrinol Invest 2006; 29: 885-7.

[77] Magiakou MA, Mastorakos G, Oldfield EH, et al. Cushing's syndrome in children and adolescents. Presentation, diagnosis, and therapy. N Engl J Med 1994; 331: 629-36.

[78] Woods DR, Arun CS, Corris PA, Perros P. Cushing's syndrome without excess cortisol. BMJ 2006; 332(7539): 469-70. 
[79] Chrousos GP. Glucocorticoid therapy. In: Felig P, Frohman L, Eds. Endocrinology and metabolism. $4^{\text {th }}$ ed. New York: McGraw-Hill 2001; pp. 609-32.

[80] Jobling AI, Augusteyn RC. What causes steroid cataracts? A review of steroid-induced posterior subcapsular cataracts. Clin Exp Optom 2002; 85: 61-75.

[81] Mankin HJ. Nontraumatic necrosis of bone (osteonecrosis). N Engl J Med 1992; 326: 1473-9.

[82] Kaplan JG, Barasch E, Hirschfeld A, et al. Spinal epidural lipomatosis: A serious complication of iatrogenic Cushing's syndrome. Neurology 1989; 39: 1031-4.

[83] Israel E, Banerjee TR, Fitzmaurice GM, et al. Effects of inhaled glucocorticoids on bone density in premenopausal women. N Engl J Med 2001; 345: 941-7.

[84] van Staa T, Leufkens H, Cooper C. Use of inhaled corticosteroids and risk of fractures. J Bone Miner Res 2001; 16: 581-8.

[85] Agadi S. Iatrogenic Cushing's syndrome: a different story. Lancet 2003; 361(9362): 1059

[86] Liu D, Ahmet A, Ward L, et al. A practical guide to the monitoring and management of the complications of systemic corticosteroid therapy. Allergy Asthma Clin Immunol 2013; 9: 30.

[87] Valin N, De Castro N, Garrait V, et al. Iatrogenic Cushing's syndrome in HIV-infected patients receiving ritonavir and inhaled fluticasone: Description of 4 new cases and review of the literature. J Int Assoc Physicians AIDS Care (Chic) 2009; 8: 113-21.

[88] Kedem E, Shahar E, Hassoun G, et al. Iatrogenic Cushing's syndrome due to coadministration of ritonavir and inhaled budesonide in an asthmatic human immunodeficiency virus infected patient. J Asthma 2010; 47: 830-1.

[89] Gupta SK, Dube MP. Exogenous Cushing's syndrome mimicking human immunodeficiency virus lipodystrophy. Clin Infect Dis 2002; 35: E69-71.

[90] Carr A. HIV protease inhibitor-related lipodystrophy syndrome. Clin Infect Dis 2000; 30: S135-42.
[91] Tirabassi G, Papa R, Faloia E, Boscaro M, Arnaldi G. Corticotrophin-releasing hormone and desmopressin tests in the differential diagnosis between Cushing's disease and pseudoCushing state: A comparative study. Clin Endocrinol (Oxf) 2011; 75: 666-72.

[92] Findling JW, Raff $\mathrm{H}$. Screening and diagnosis of Cushing's syndrome. Endocrinol Metab Clin North Am 2005; 34: 385-402, ix-x.

[93] Bruni FM, De Luca G, Venturoli V, Boner AL. Intranasa corticosteroids and adrenal suppression. Neuroimmunomodulation 2009; 16: 353-62.

[94] Tempark T, Phatarakijnirund V, Chatproedprai S, Watcharasindhu S, Supornsilchai V, Wananukul S. Exogenous Cushing's syndrome due to topical corticosteroid application: Case report and review literature. Endocrine 2010; 38: 328-34.

[95] Kannisto S, Laatikainen A, Taivainen A, Savolainen K, Tukiainen $\mathrm{H}$, Voutilainen R. Serum dehydroepiandrosterone sulfate concentrations as an indicator adrenocortical suppression during inhaled steroid therapy in adult asthmatic patients. Eur J Endocrinol 2004; 150: 687-90.

[96] Foisy MM, Yakiwchuk EM, Chiu I, Singh AE. Adrenal suppression and Cushing's syndrome secondary to an interaction between ritonavir and fluticasone: A review of the literature. HIV Med 2008; 9: 389-96.

[97] John G, Ollo D, Meyer P, et al. Clinical course and management of iatrogenic Cushing's syndrome after co-administration of injectedtriamcinolone and ritonavir: A systematic review. J Antivir Antiretrovir 2013; 5: 180-4.

[98] Krasner AS. Glucocorticoid-induced adrenal insufficiency. JAMA 1999; 282: 671-6.

[99] Wlodarczyk JH, Gibson PG, Caeser M. Impact of inhaled corticosteroids on cortisol suppression in adults with asthma: A quantitative review. Ann Allergy Asthma Immunol 2008; 100: 2330

(C) A.V. Raveendran; Licensee Bentham Open.

This is an open access article licensed under the terms of the Creative Commons Attribution Non-Commercial License (http://creativecommons.org/licenses/by-nc/3.0/) which permits unrestricted, non-commercial use, distribution and reproduction in any medium, provided the work is properly cited. 